\title{
ROLE OF POLITICS IN PUBLIC SECTOR ORGANIZATIONAL CHANGE
}

\author{
Ruth Sepper ${ }^{1}$, Ruth Alas ${ }^{2}$ \\ ${ }^{1}$ Tallinn University of Technology, Ehitajate tee 5, Tallinn, Estonia \\ E-mail:ruth.sepper@ttu.ee \\ ${ }^{2}$ Estonian Business School, Lauteri 3, 10114 Tallinn, Estonia \\ E-mail:ruth.alas@ebs.ee
}

Received 11 April 2007; accepted 7 November 2007

\begin{abstract}
In this paper we will address issues of organizational changes in public sector where the relevance of management has not diminished during the last two decades of the neo-liberal market philosophy. Public sector organizations are susceptible to greater and more open accountability with politicians, pressure groups, taxpayers and voters all having an interest in the performance of it. In late 1990s Estonian government initiated reforms of health care system in the country. Estonian Hospital Master Plan (EHMP) 2015 was launched in 2000 which, within the others, was initiating the merge of seven Tallinn hospitals into North Estonian Regional Hospital (NERH). To evaluate efficacy of organizational changes during implementation of EHMP-model into health care system in Estonia we utilized personal interviews of top and middle managers and annual reports of merged hospitals to benchmark these measures to earlier merged Univerity Hopsital and other EU hospitals.

We conclude that even NERH was established and the reform-initiated changes were mostly introduced by the deviation from first-line governmental plans and introduction of new political directions in 2003 lead to new organizational changes and managerial efforts to gain the goals with, unfortunately, prolonged change process.
\end{abstract}

Keywords: organizational change, public sector, politics.

\section{Introduction}

Recently transformed from being an authoritarian, centralized, totalitarian socialist state to a democratic country with a free market economy has made the management of change a major issue in Estonia. The post-communist transformation provides settings actually in the process of being demolished that are very different in their characteristics and within which discontinuities are more fundamental and the change is less constrained by institutional framework. Scholars of organizational change have tended to have their focus restricted, because of the normal socio-economic context in which they work, by changes in public opinion, legal conditions and similar discontinuities within the social structures (Clark \& Soulsby 1999). Institutional theory is concerned with examining the external pressures from stakeholders in the social and economic environment and their influences on organizations to provide the understanding of the relationship between the organizational structures and the wider social environment in which organizations are situated (Khadaroo 2005: 72). Strategic management in the public organi- zations has some specific features. The creation of the mission of the organization, the first step in strategic planning, requires careful review of the organization's mandates - the requirements imposed by external authorities through legislation and regulations (Rainey 1997). There are more political intrusion into management in public organizations and a greater infusion of political criteria. Strategic planning is also more difficult in public sector because of the sort-term considerations of politicians (Lawton and Rose 1994).

There are studies about behavioural factors influencing organizational changes in Estonian companies (Alas \& Sharifi 2002; Alas \& Vadi 2004; Alas \& Vadi 2006), but changes in public sector have not got researchers' attention.

The relevance of public sector management has not diminished during the two decades of hegemony for the neo-liberal market philosophy (Lane 2000). In this paper authors address the issues of management of change in public sector by using an example of Estonian hospitals. 


\section{Estonian hospital reform}

Estonian Health Project was started in 1995 to support health care reform initiated by the government. Estonian Hospital Master Plan 2015 (EHMP) has been initiated by the Ministry of Social Affairs in 1999 (Scandinavian Care Consultants AB and SWECO 2000). EHMP analysis showed there were 78 hospitals providing over ten thousand hospital beds in Estonia. Most of the hospitals were over 20 years old and generally in poor condition. The project supported the health care reform initiated by the Estonian government by offering recommendations regarding the future hospital network based on the best practice in Europe implying to the quality and efficiency:

a) decentralization of the simple and centralization of the difficult processes, b) more out-patient and less inpatient care with significant reduction, on the average, the length of stay in hospital (ALOS), c) prefer day care, day surgery, new less invasive diagnostic and treatment modules with the emphasis on quality of life, d) utilize new potent drugs.

The final report of the project was produced in April 2000. The task set by EHMP included reference to the main influences in modern health care delivery in Western countries. The Emphasis was placed on the hospital networks (Scandinavian Care Consultants AB \& SWECO 2000). There were very clear recommendations with regard to the (a) future catchment areas, and (b) the organization of the hospitals within each area.

EHMP proposed the establishment of four main catchment areas or regions in Estonia: Northwest, Northeast, Southwest and Southeast. Each catchment area should have a hospital structure, which provides for a regional/ university hospital (in Tartu and Tallinn) and/or central hospitals (in Haapsalu, Kuressaare, Narva, Paide, Rakvere, Viljandi and Võru). EHMP drew attention to the urgent need for updating the hospital infrastructure. The general environment within the hospitals was recorded as being unsatisfactory for both patients and staff. It also recommended that the implementation of this structure should be linked to the benchmark/standards for clinical performance.

Total number of hospital beds should decrease to 3100 . Calculated investments for hospital network renovation was 4,4 bil EEK (1 EUR = 15,64 EEK). Planned costs and capital assets should be achieved by 2015 . Renovation and building of new hospitals has to follow suitable standards for gross bed area. ALOS has previously never been a factor of great importance in Estonian health system. Modern Western health care systems look at ALOS as of major importance either in medical or economical terms. Proposed by EHMP ALOS should reach to 4,5 in the 2015 perspective (Scandinavian Care Consultants AB \& SWECO 2000).

EHMP was a modern look at hospital network having very ambitious goals. NERH was founded according to EHMP directed Business Planning for NERH in 2001 (NERH 2000). Main directions for changes in the hospital network were included in the feasibility study for Tartu University Hospital (Newspaper of Clinicum 1999), development plan for Estonian hospital network 2015 (Estonian Hospital Network for 2015, 2000) and business planning for NERH (NERH 2000). The first study evaluated health care system in the Southern part of Estonia with special respect to TUC feasibility. Final report evaluated TUC needs for investments either in technology or renovations (Newspaper of Clinicum 1999). Prognosis for hospital beds needs, the measures for work load with the recommendation to follow the so-called green field development where new building holds $71935 \mathrm{~m}^{2}, 1280$ hospital beds with $56 \mathrm{~m}^{2} /$ bed in the hospital. Investments need is 1,4 billion EEK (Newspaper of Clinicum 1999). Development Plan for Estonian Hospitals Network (DPEH) was launched and officially upheld in 2003 by MSA statement nr 103 (Estonian Social Ministry 2002). DPEH was positioned as a plan applying EHMP in practice (Bakler 2003). In DPEH document the aims of the Plan are similar to EHMP aims: (a) to ensure the access to medical care, (b) to optimize expenditures to setup and functioning of hospital network and (c) to ensue sustainable development of the hospital network (Bakler 2003). In the preamble of DPEH it is admitted that the document has the goal to work out options for hospital development, whereas principal standpoints of all previous plans are taken into consideration. The goals of hospital network rearrangement are similar to these in EHMP, the contraversary is appearing in many parts. The local hospital definition was added to hospital definition: local hospital is needed in the centers which are situated from regional hospitals as far as $70 \mathrm{~km}$ and in which catchments where there are up to 40000 people. This hospital enables to provide 24-hour emergency care excl. emergency surgical care (e.g. Rapla, Jõgeva, Põlva hospitals).

Total number of hospital beds should decrease to 3730 (3100 in EHMP) with total investment costs of 5 billion (4,4 in EHMP) EEK. Also, in DPEH the merge of Tallinn Children Hospital to NERH was not mentioned (Bakler 2003).

In order to consolidate and downsize services within NERH in conjunction with a transition to average lower lengths of stay (ALOS), greater use of day stays and 
ambulatory procedures in line with good practices in OECD and EU countries, a business case was analyzed for different options. As an option, doing nothing could not achieve any significant alterations in the existing hospital or service structure, and so it was quickly put aside. The option to build a new so called Greenfield entity was put aside as unrealistic because of the investment requirements. Also, doing the minimum, for example, simply rationalizing the management opportunities created by the single entity of NERH, would not create any change neither to the acute service configuration nor to the clinical support facilities. The option known as Master Plan assumed the consolidation of NERH activities at Mustamäe site, once the new facilities were built for the hospital. Other NERH sites would be disposed of after such consolidation. This option assumes that ALOS can be reduced to 4.5 days translating into a reduction in the number of beds to 598. The management team proposed choosing the rationalization option in the short and medium term and Master Plan B in the long term. The supervisory board decided to approve this option as the strategic development plan for NERH (NERH 2000).

\section{Estonian Regional Hospitals as the Objectives of the Change}

NERH was established on July 25,2001 . Seven statehold hospitals merged and consolidated hospital started to act on October 1, 2001. The vision of NERH in 2001 was to be a patient-friendly regional hospital with high treatment quality. New vision from 2005 was to be a competitive medical center in the European Union. In order to fulfil the vision NERH three high-level strategic objectives: have been brought out a) to achieve steady improvement in treatment quality and growth of patients' satisfaction, b) to increase a market share in special health care and to offer a wider range of specialities, c) to reach a state of an efficiently managed organization, and in 2005, more objectives were added, d) together with medical service delivery research, medical training are the main goals of NERH.

The Faculty of Medicine was one of the first four faculties in Tartu Academia Gustaviana University (1632-1656). When Estonia regained independence, the re-establishment of the Hospital came high on the agenda. A state-of-the-art and constantly developing training hospital united different profile clinics. The first steps were taken in 1993 when an umbrella organization called Tartu University Hospital was set up. In January 1998 the Government of the Republic of Estonia, the University of Tartu and the city of Tartu concluded a cooperation protocol and on December 22nd, 1998 the Foundation of Tartu University Hospital was established. TUC vision in 2005 was that the hospital is the flagship of Estonian medicine with the mission to ensure the continuity and development of Estonian medicine through high-level integrated medical treatment, training and research. Structure of TUC is in Fig. 1.

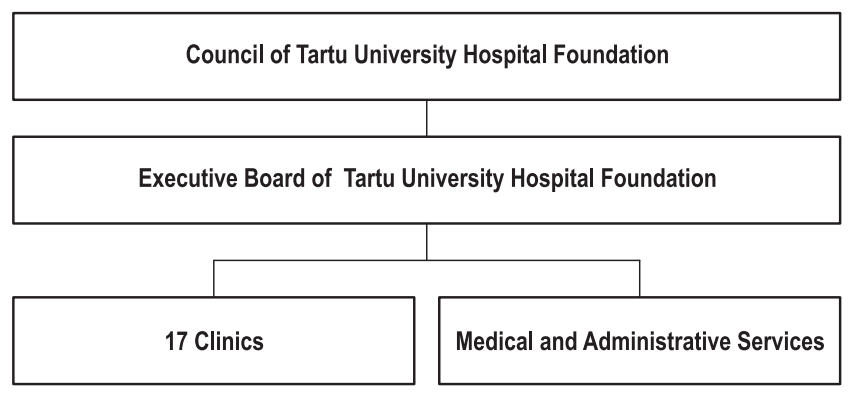

Fig. 1. Structure of TUC

\section{Changes Carried Out by Change Management in NERH according to EHMP}

According to EHMP the merger of seven of Tallinn hospitals started in 2001 with the formation of NERH. Managerial changes occurred throughout all managerial areas - a new vision, mission and strategy were worked out, human resources were revised via a publicly announced personnel search to locate the best specialists (physicians, chief doctors, chief nurses), the structure of the organization was completely re-organized as a result of which four principal divisions began managing the main functional units (internal medicine, surgery, diagnostics and psychiatry) and the financial operations and budgeting were consolidated using an infotechnology supported financial program. It is worth noting that during the initial stages of the merger and the consequent changes, a negative financial performance of about $40 \mathrm{~m}$ EEK was expected for the next budgeting period. Therefore, it was decided by NERH managerial board that the preferred development strategy for NERH was to pursue rationalization activities during the initial period of stabilizing the organization, and then the changes were successfully implemented throughout the organization and the financial state was stabilized in order to plan and pursue Master Plan option to achieve an optimal size.

NERH strategy was (NERH 2000) a) to achieve a steady improvement in treatment quality and the growth of patients' satisfaction, b) to increase a market share in special health care and to offer a wider range of special services, c) to achieve an efficiently managed organization where the consolidation and downsizing of services within NERH were implemented. 
In order to fulfil these three strategic objectives the managers of NERH discovered the following critical factors. As an organization providing medical services, the main issue and the basis for success in the future is to achieve the best treatment quality in the country. This relates to three critical success factors and directions of change and management of a) employees, b) working environment, c) patients' satisfaction. The most important part of the management of these changes towards generating a new vision of treatment quality was working with the personnel - the doctors, nurses and other specialists. NERH is an intellectual organization, and its principal capital resource is human capital - the employees providing medical services. In order to make changes in that direction a new structure (principal and support processes), personnel policy, clients' service re-arrangement, renovations were planned as the managerial tools for these changes.

For this purpose, an appropriate change management program was introduced covering critical areas like communicating the change rationally, achieving employees' participation and motivating them to act. The objective of the change management program was to guarantee that the whole organization understands and acknowledges the new corporate objectives and is willing to fulfil them.

In order to achieve the second strategic objective of $\mathrm{NERH}$ - an increase in its market share - it is critical to increase brand awareness through certain marketing activities stressing the high quality of treatment at NERH. In addition to public opinion, the close and mutually beneficial relationship, not only with Health Insurance Fund (EHIF), but also with all other health-care institutions, e.g. general practitioners, polyclinics and other hospitals, is essential. The introduction of new specialist areas to NERH portfolio allows further enlargement of its presence in Estonian health-care market.

In case revenues come under pressure and competition becomes fiercer, efficiency becomes a more and more important factor while achieving competitive advantage. Increasing efficiency can be divided into two wider areas of optimization - core processes and support functions. Constant process analysis and optimization are extremely important under a cost reduction program as it enables to use the resources in a more efficient way. Processes in accordance with predetermined conditions and specifications are of utmost importance both in terms of cost as well as quality. To meet established standards, a new process of internal control was introduced.

The use of IT solutions has become a more important tool for efficiency in medical enterprises. Thus, proc- esses must be supported by IT solutions such as electronic patients' records, inventory management and procurement functions. In order to improve resource allocation and better management, these modules should be integrated into the financial accounting system. However, an IT-based hospital information system supporting all processes as an entity was the final aim of that activity.

By concentrating attention on the critical success factors and aligning the organization through the action, it was possible for the management board to fulfil all the strategic objectives. During the second half of 2001 and beginning of 2002, most of the upper and middle management, including all heads of clinics, were appointed. This guaranteed a comprehensive understanding and implementation of the rationalization plans.

\section{Methods and data}

Matrix of methods used for the evaluation of organizational changes is in Fig. 2.

\begin{tabular}{|c|c|c|}
\hline & Clinical & Economic \& Managerial \\
\hline Quality & $\begin{array}{l}\text { Evaluation of in- and out-patient care } \\
\text { Evaluation of personnel performance } \\
\text { Benchmarking process measures }\end{array}$ & $\begin{array}{l}\text { Organizations' diagnostics } \\
\text { Benchmarking (Annual Reports) } \\
\text { Interviews with top managers }\end{array}$ \\
\hline Efficiency & $\begin{array}{l}\text { Benchmarking health care indicators } \\
\text { (ALOS, beddays, hospital admissions, } \\
\text { BOR, day care, in-patient care) }\end{array}$ & $\begin{array}{l}\text { Evaluation of managerial tools } \\
\text { Benchmarking of financial measures } \\
\text { Interviews with top managers }\end{array}$ \\
\hline
\end{tabular}

Fig. 2. Matrix of methods used

All collected data were taken from the Annual Reports from analyzed hospitals (NERH of 2002, 2003, 2004 and TUC of 2001, 2002,2003). Seven interviews from 12 collected are cited and opinions of interviews subjects have been used.

\section{Characterization of the analyzed hospitals}

NERH holds many strong trademarks in Estonian medicine (Mustamäe Hospital, The Cancer Centre, etc.) and employs the best-qualified physicians in the country. It aims at becoming the leading hospital in Estonia providing a full range of medical services. The merger of seven state-owned hospitals was performed to comply with the provisions of Health Care Act (5), which prescribes that hospitals will be established as foundations or limited companies under the private law. NERH is a foundation. The founder of NERH is the state. The consolidated turnover of these merged hospitals was 494 m EEK in 2000. Their consolidated operating result was a loss of 27,6 million EEK in 2000 and in 2002-2004, is shown in Fig. 3. 


\begin{tabular}{llll|}
\hline & 2002 & 2003 & 2004 \\
Net Turnover $^{1}$ & 666029 & 715179 & 840969 \\
Cash Flow $^{1}$ & 3427 & 31126 & 48045 \\
1 - ${ }^{103}$ EEK & & & \\
\hline
\end{tabular}

Fig. 3. The consolidated turnover and cash flow of NERH in 2002-2004

The consolidated turnover of TUC was $571 \mathrm{~m}$ EEK in 2001. Their consolidated operating result was a loss of 37,2 million EEK in 2001 and in 2002-2003, is shown in Fig. 4.

\begin{tabular}{llll|}
\hline & 2001 & 2002 & 2003 \\
Net Turnover $^{1}$ & 571179 & 628179 & 794306 \\
Cash Flow $^{1}$ & -37208 & 10186 & 13279 \\
1 1- ${ }^{103 ~ E E K ~}$ & & & \\
\hline
\end{tabular}

Fig. 4. The consolidated turnover and cash flow of TUC in 2001-2003

\section{Analysis of benchmarked data}

The merging of seven Tallinn hospitals started in 2001 with the formation of NERH. At the end of 2003, Keila hospital, situated $25 \mathrm{~km}$ from Tallinn, also joined NERH. Changes occurred throughout all managerial areas; a new vision, mission and strategy were worked out in 2001-2002. Three critical success factors were revealed from this process - employees, work environment and patient/client satisfaction.

During 2001 and 2002, an analysis of the demand for labour and standardization of the workforce took place. Employees from both medical and support processes were identified, analyzed and optimized for the new structure. The new structure included four (and since 2003 five) different divisions - surgical, internal and psychiatric methods of treatment and diagnostics including the principal diagnostics divisions together with anesthesiology and intensive care. The changes made to the structure were reflected positively in the consolidation of resources in general and financial resources in particular. The day-to-day management of the new consolidated structure was also more effective.

The process of hiring specialists through open competition provided posts proceeded by great interest among employees both inside and outside the hospital.

Different teams of nurses and physicians worked to form the basic principles for a system of motivation and payment in NERH. Both groups proposed a simple transparent payment system.
EHMP was, at least in part, initiated because of the unsatisfactory of environment for both patients and personnel in Tallinn hospitals. NERH started renovations soon after the merge and by the end of 2004, was able to create a competitive advantage for the organization through these renovations and other investments. Large relocation plans, excluding oncology, were completed in 2003. Functional planning for a new technology building and the renovation of old buildings to provide new wards have made some progress. It has been especially important that support has been gained from the EU structural founds, which ensures the steady development of NERH. It also shows that government authorities trust NERH as a partner.

There has been a successful centralization of the systems for accounting and purchasing of medical supplies. The end of 2002 already centralized most of the support functions. The savings have been estimated as being as high as $30 \%$. General financial figures are in Fig. 5.

\begin{tabular}{|llll|}
\hline & $\mathbf{2 0 0 2}$ & $\mathbf{2 0 0 3}$ & $\mathbf{2 0 0 4}$ \\
Working capital ratio & 0.9 & 1.3 & 1.1 \\
Quick ratio & 0.7 & 1.1 & 1.5 \\
Debt to total assets ratio (\%) & 21 & 21 & 25 \\
EBITA (EEK) & 33020 & 64146 & 29095 \\
\hline
\end{tabular}

Fig. 5. General financial figures of NERH, 2002-2004

An important step forwards involved an association with European Quality Award system. The envisaged systematic approach represented a remarkable start to implementing quality management in the entire NERH.

\section{Benchmarking of annual reports of NERH vs. TUC toward medical and economic efficiency}

Analysis of managerial success and sufficiency in NERH from 2001 to 2004

Financial funding of Estonian hospitals occurs via EHIF. Almost $97 \%$ of year budget income is financed by EHIF. Hospitals budget volume is related to the operational results of the hospitals from the previous economic year. EHIF mainly stays after equal attainability of medical services to all habitants is covered by solitary health insurance. The budget of hospitals is based on treatment cases (either in- or out-patient) and on the previous cost per case. Thereafter, budgeting process occurs by negotiations between managers of EHIF and hospitals on the basis of previous economic year achievements either in medical or economical operations. 
Not less important in successful negotiations are the relationships with central hospitals, general practitioners and other medical service suppliers of the whole catchment area. These contacts and the cooperation are somewhat a key issue to gain success in budgeting process with EHIF every year.

According to the results the net-turnover (NT) of TUC shows more rapid growth than that of NERH $(16 \%$ vs $11 \%$, respectively) mostly in favour of EHIF income growth (10\% vs $22 \%$, respectively). Importantly, income coming from the sold services to other hospitals and medical service suppliers is largely bolder in TUC. This income is not directly related to EHIF budgeting but is directly related to relationships between the medical enterprises encouraged by hospital managers. It also shows that free resources (either hi-technology or labour) outside to serve EHIF budget are significantly more utilizable in TUC than in NERH.

\section{Analysis of Expenditure patterns and management}

Total costs of both enterprises are growing. Comparing NT growth to total costs growth it is seen that NERH reveals the trend where total costs growth exceeds NT growth (3\% to $23 \%$ vs $7 \%$ to $18 \%$, respectively, total costs vs NT). TUC has the trend of NT growth from $10 \%$ to 26 compared to total costs growth from $7 \%$ to $23 \%$, which shows that NT growth covers the total costs growth.

The labour expenditures in both TUC and NERH have the highest ratio of total costs. However, NERH expenditure level is declining whereas TUC is more or less stable. Also, labour costs are growing in TUC more rapidly that in NERH. However, the labour force costs covered by NT is equal in both hospitals. To compare, HUCS expenditures to labour is almost $61 \%$ of NT, growth from year 2002 to 2003 was $2 \%$ (in TUC $24 \%$ and in NERH $14 \%$ ).

Medical operations are the main process in the hospitals. To date, medical operations in both TUC and NERH are handled so that labour expenditures are the part of fixed costs. Variable costs include the expenses directly used for diagnosing and treatment processes (costs for medicines and supplies). The Main process operational/variable costs are highly growing in both hospitals whereas the variable costs growth exceeds significantly NT growth especially in NERH $(11 \%$ and $8 \%$ in 2003 and 2004) but also in TUC (6\% and $1 \%$ in 2002 and 2003). The ratio of variable costs in NT is $28 \%$ in both hospitals.

Ratio of fixed costs (including labour costs) to NT shows the decline in both hospitals. Inventory in the hospitals is significantly higher in NERH than in TUC, also inventory turnover verifies too large stock reserve.

\section{Analysis of efficiency of core processes}

Hospitals open the hospital beds to diagnose diseases and treat patients. Number of hospital beds should cover the needs of in-patients medical care in the service area. The number of hospital beds needed is related to patients' flow and the service level of the hospital. The Key issue in predicting hospital wards capacity is efficiency of medical process the hospital can achieve; number of beddays, bed occupancy rate and ALOS (total number of occupied hospital bed-days divided by the total number of admissions or discharges; length of stay (LOS) of one patient $=$ date of discharge - date of admission, if these are the same days, then LOS is set to one day) are reflecting process efficiency of the hospital.

The use of hospital beds fund in both benchmarked hospitals is not efficient enough (70-77\% in NERH and $77-81 \%$ in TUC). For comparison, in Western European countries such as Ireland (83-85\%), Norway (85-88 \%), Denmark (83 \%), Switzerland (85-86 \%) (HFA-DF 2005) the use of opened hospital bed fund is significantly higher than in the benchmarked hospitals. Also DPEH predicted BOR (average number of days when hospital bed was occupied as \% of available 365 days) not less than $83 \%$. However, entire Estonia has BOR of 60-65\%, other Baltic countries like Lithuania $76 \%$ and Latvia $79 \%$ (HFA-DF 2005). Also BOR in days (average number of days when hospital bed was occupied as days of available 365 days; calculated as beddays per number of opened hospital beds for a certain period) shows inefficient occupancy of opened hospital beds (max 274 in NERH and 295 in TUC).

\section{Analysis of general management of changes initiated into the health care system}

EHMP proposed the basis for further hospital network planning. Critical success factors were quality and efficiency in operations. This proposal also took into consideration that initiative and coordination of that, the principal and very large change plan in the medical care system in the country will be taken by Government, thereafter MSA. Also, no competitive reorganization was proposed in terms of financing, the merging of hospitals, and, importantly, in profiling (licensing) the level (tertiary and secondary care) of medical services the hospitals will be allowed to give in the future network. During the years TUC started as a consolidated university clinicum in 1998 and the year 2001, 
when seven hospitals merged into NERH, this central initiative was worked out by all organizations around the hospitals and by hospitals themselves.

In 2002, a new Development Plan for Estonian Hospitals (DPEH) was launched and officially upheld in 2003 by MSA statement nr 105. DPEH was positioned as a plan applying EHMP in practice (Bakler 2003). In DPEH document the aims of the Plan are similar to EHMP aims:

a) to ensure the access to medical care;

b) to optimize expenditures to set up the functioning of hospital network and

c) to ensure sustainable development of the hospital network.

However, more detailed explanation why a new plan was needed is given by Mr. Tarmo Bakler, the leader of Estonian Health Project 2015 in his article to Eesti Arst in 2003 (Bakler 2003). The author alleges that the application of EHMP was limited because:

a) the plan focuses on final aims instead of transition processes assuming that Estonian state can manage needed changes;

b) the plan focuses only on acute medical care with no attention to the care of mental disorders, tuberculosis and long-term and rehabilitation care;

c) the plan did not take into consideration traditional regional centers and logistics between them;

d) this proposal is based on medical quality and economic efficiency only with no attention to regional interests to restore previous hospitals.

Reading this evaluation to EHMP it is suitable to mention that the treatment and diagnostic quality of medical services is the main approach of modern medicine. All efforts given to new technologies, treatment guidelines or operational changes gather quality dimension. In modern medicine, patients quality of life has gained a very important part in evaluation of medical services. Modern medical quality is always associated with efficiency; new technologies allow more out- than inpatients' care, more day care with less invasiveness, etc (Ginsburg 2004). This all leads to economical efficiency of medical operations. Both the first and the last comment of the author are referring to changes needed in the society and change management carried out according to EHMP. Changes are always processes, which are not welcomed, neither in the larger environment nor in a single enterprise. Changes should always be carefully planned and prepared which is the common knowledge of change management. For example, health care spending grew slowly in the mid-1990s starting to grow quicker in the last decade (Strunk,
Ginsburg 2004). One of the main reasons why the mid-1990s were outstanding because there was a good manager-care compared to the last decade with a clear manager-care bust (Strunk, Ginsburg 2004). Typical resistance to changes is described in sentence (d) in the cited article (Bakler 2003). The first (a) critical note refers to poor managerial quality in Estonian medical system.

Additional explanation why previously planned changes were reconsidered can be found in the article by Jesse and her colleagues (2004), where authors point out to negative publicity surrounding the plan and the demand of specialists organizations to evaluate the plan and develop separate plans (DPEH 2002). All this initiated new political initiatives resulted in DPEH. It envisaged 21 hospitals being eligible for long-term contracts with EHIF and state investments. The plan together with specialists association development plans were taken into account in developing criteria for hospital licensing and for regulating the types of services that hospitals at different levels are allowed to provide (Statement of Ministry of Social Affairs Estonia 2004). Also a new type of hospital was added into the network called local hospitals. The implementation of the new Health Service Organization Act in 2002 (Health Service Organization Act 1994) clearly defined all medical service providers as private entities under the private law with public interests represented through public membership of supervisory board (Kiivet \& Harro 2002; Jesse et al. 2004).

Overall, the hospitals are now quite independent enterprises with independent management with chairmen and CEOs of the boards. Councils of NERH and TUC consist of councillors from MSA and different political parties. Councils of Tallinn central hospitals consist of leaders of Tallinn Municipal Corporation and councillors from different political parties. Governmental managerial initiatives are carried out via Acts and Statements. A new health care politics, which should hold the initiative and coordination of health care system in Estonia, has lately been started in MSA. However, until then, independent and often controversial developments of the hospitals deviate largely from that proposed either by EHMP or DPEH (Võrk et al. 2005), which already is seen in the budgets of hospitals.

\section{Analysis of NERH managerial success and sufficiency in 2001-2004}

To summarize the general managerial change process occurring so far in NERH, it must be said that the time taken for these major transformations was too long. This factor is in fact extremely critical for achieving 
success. The awareness of the need for the change and the readiness to undertake the change varied greatly between employee groups, and this heightened the potential for miscommunication and mistrust of managers. It is vital to gain the support of the personnel in the change initiatives, however, the aims and expected results of the change process were not communicated clearly enough to the personnel.

The urgent need for a better policy and strategy for internal communication within the merged hospitals still exists. This activity was neither highlighted nor stressed sufficiently in the rationalization plan of 2001, and remained unresolved at the end of 2004 and beginning of 2005. People were not prepared for such large changes and resistance became evident. The internal communication system was incapable of supporting the change processes sufficiently. E.g. the new structure included four very large clinics where information had to move down through at least four levels to achieve its target. The Access to information was said to be poor causing mistrust of the managers among employees and the resistance to the change. In 2003, a new structural unit, the anesthesiology clinic, was established. The creation of that unit was not a part of the rationalization plan but a failure especially because of poor readiness for the changes among employees before the implementation of EHMP started.

Nevertheless, the new consolidated structure in general not only gave to NERH its first opportunities to invest in technology and the work environment for many years, it also united the merged hospitals into one large hospital - NERH.

Competitive recruitment in NERH occurred together with a certain amount of selective headhunting. This was manifested especially in the recruitment of staff for new specialist units for NERH. Unpleasant attacks on the part of the media and misinformation provided to EHIF by competing hospitals showed the urgency of the need for consolidating all medical service providers in the north of Estonia. This case occurred because of managerial deviation from EHMP proposal. It is worth noting that this is still incomplete.

Although people were very active in competing for provided posts, frustration in an attempt to win the desired post was not uncommon. The reason for that, at least in part, was the belief from the Soviet times that no position was comparable and getting a job was a certainty. However, there was a positive feedback about this competition from those who were successful, whose self-confidence and readiness for the change increased.
These newly selected employees created a positive basis for the change of management in each department.

However, some departments are still disturbed and are against the competitive recruitment. In 2005, managers of NERH changed the system so, that doctoral level of posts did not fit the terms of contracts. Partly, it was initiated by the scarcity of labour in Estonia.

To date, the new units with their new specialists have commenced work with outstanding results in NERH a stable, well-organized and well-financed level of service was obtained by the end of 2004. Thus, in only two years and a half starting from a zero, the newly established specialists' units became a natural part of NERH medical process. Moreover, these specialists' units consolidated naturally with the previous units and outstanding medical synergy has been achieved in at least one area (the centre for internal diseases). This represents one of the most positive results in the history of NERH improving treatment quality, internal effectiveness as well as personal competence and satisfaction with the work and the work environment. It shows that changes which are carefully planned and prepared give a flourishing result either in the main process quality or economical efficiency.

As the issue of payment and motivation is rather an emotional one for the staff, even minor details within the system that indicate mistrust may lead to dissatisfaction and instability among the personnel. Again, NERH was confronted with poor internal communication during that particular process, which led to a long and emotional dispute between employees' groups and managers. The price of such a managerial mistake was: a) the loss of time, and b) mistrust between the two parties and more importantly, a loss of resources. This process is still going on.

\section{Analysis of expenditure patterns as a results of changes}

Health care costs are rapidly increasing all over the world. The simple explanation is that people are getting more medical care. Additionally, population in Western countries is eldering, the increased need for medical care is elsewhere. Over the long term, new medical technology has been the dominant driver of increases in health care and insurance costs. New technology includes not only new diagnostic procedures and treatments that are more costly than older ones, but also some cost less per unit but are more effective and cause less discomfort to patients - qualities that stimulate much higher rates to use. Additional applications of established technologies, e.g. magnet resonance imag- 
ing, computer tomography imaging, positron emission tomography, etc., may be even more important to cost increases than technologies that are being applied to medical care (Strunk \& Ginsburg 2004; Nichol 2002). Health care economics has given a new insight to many previously largely used technologies evaluating these according to patients' quality of life and cost-effectiveness. E.g. well-known and largely used tonsillectomy does not effect on either patients' quality of life nor on health care costs decrease. However, the queue to wait for tonsillectomy in Estonia is almost four years. Health care economical approaches should be further implemented (Võrk et al. 2005; Jüristo 2004).

Nichol (2002) from Employee Benefit Research Institute from Washington D.C. says that changing technology in medicine results in increased spending and accounts for a half or two thirds of the increase in health care spending in excess of general inflation.

Ginsburg (2004) from the Center for Studying Health System Change in Washington D.C. comments that these results would be different if these technologies were used more judiciously, with greater guidance of research on medical effectiveness.

Benchmarking of two hospital expenditure patterns shows the same trend as elsewhere in the increase of health care costs. However, TUC managers have been more successful in budgeting process with EHIF than NERH managers, the growth of total costs exceeds NT growth in NERH. Expenses in medical operational costs are increasing equally in both hospitals showing marked increase $(12 \%$ and $11 \%$ in NERH and TUC, respectively). Inflation in Estonia is not over $4.5 \%$. Thus, most of the costs increase is associated with appreciation of the medical process.

Expenses in labour force in both hospitals have covered almost half of NT of both enterprises. TUC had stabilized its structure and optimized staff many years earlier than NERH did, which is evidently the reason for fluctuation of NERH labour costs compared to TUC. Considering the growing potential of labour force because of migration around EU the lack of employees in the health care system can lead to the increase of labour costs elsewhere (Kallaste \& Philips 2004).

Managerial problems were also revealed by inventory reserve in NERH. TUC implemented the special ITsupported program for stock and provision balance and this is seen from the inventory turnover and reserve. NERH is just supplying the system.

Controlling health care costs as an approach stresses on administrative controls relying on tools such as restric- tive provision of resources (supplies and medicines), regulation of facility expansion, guidelining all medical technologies and following the guideline restrictions, which, however, proved highly unpopular. Decentralization of managerial decisions to the closest level on medical process might be the key to the decrease of medical care costs. However, it cannot be achieved at the expense of medical quality.

\section{Analysis of medical efficiency and quality management}

In a modern hospital medical and economical quality and efficiency are largely integrated. They can potentate or, on the contrary, destruct each other. Parameters characterizing medical quality\&efficiency are also a part of economy, e.g. ALOS, beddays, BOR, ratio between in- and out-patients' care, day care, access to diagnostic tools and facilities, etc. This is clearly declared by hospital visions, missions and goals.

Both hospitals have similar aims to increase out-patients' services. Out-patients' visits growth has equal trend to increase, which shows a good access to medical services and, on the other hand, higher turnover and inexpensive services. An important value of modern hospitals is a tendency to increase either out-patients' or day care surgery. This process is supported by modern technology of surgery, anesthesiology and postoperative care. Even later mentioned is associated with expensive investments for the hospital it increases the service turnover with less harm to patients. Furthermore, increased proportion of surgery in favour of outpatients' and day care gives to the hospital possibility to reduce ALOS, and furthermore, the beddays subsequently with reduction of the hospital bed fund. This positive circulus vitiosus is mediated by high technology and technological processes with IT support. According to the results TUC has great tendency to increase out-patients' and day surgery with the decrease of ALOS, especially of ALOS of acute care. Technical and technological backwardness of NERH for almost one investment cycle from TUC is one of the major reasons why efficiency of medical process is not attainable. This is closely associated with professionalism of personnel and with interdisciplinary cooperation within the medical process, two major measures of medical quality. Professionals are looking for modern work environment to ensure their personal development. Last year or so, NERH has faced problems with job-leavers among specialists mainly because of insufficient work environment. No doubt, there are also other important factors influencing satisfaction with a job, however, 
provided good possibilities for personal development is one of the most popular value among doctors.

Overall, clinical/medical quality is closely associated with medical efficiency, which is the foundation of economical efficiency of the medical process. Proper managerial know-how from top to middle managers should orchestrate "this ensemble" for development.

\section{Conclusions}

Current study evaluated retrospectively efficiency of managerial changes made during implementation of EHMP model into North-Estonian Regional Hospital. Comparison and benchmarking to TUC has given an overview of results gained with induced changes in NERH, TUC and entire Estonian health care system.

Analysis comprised several parts of hospital management:

1) analysis of general management of changes initiated into the health care system;

2) analysis of managerial success and sufficiency in NERH from 2001-2004;

3) analysis of expenditure patterns and management;

4) analysis of medical efficiency and quality management.

Results achieved show a deviation from previous plans postulated by EHMP had strategically influences on the development of hospital network. NERH was established by means of EHMP as a tertiary care hospital with expected concentration of all medical specialities under it. No competitive approach in terms of service licensing, EHIF and EU basic funding was planned for the new Hospital Network. In 2005 it was evident, that hospitals within the Network were more or less independent in the strategical plans with no general leadership on the entire Network development. It has led to an unconstructive approach to different medical services rendering, to investments and to EHIF yearly funding of the medical services. Citizens have reacted with mistrust to health care system developments, which created large negative publicity around it. Insufficient resources to fund health care demands have led to long discussions around the state budget with no positive approach.

The end of 2003 completed most of the changes that were part of the planned rationalization in NERH. This resulted in the stabilization of the hospital finances and its capability to invest in the organization physical assets. However, new political pressure on the financing of the health care sector at the end of 2004, may lead to a reconsideration of previous development plans. This may in turn lead to the adoption of strategies associated with the professionalism of medical personnel and the hospital strategic capital. So far NERH management team has assumed that critical success factors are activities, issues or processes that should be carried out, attended to, or implemented in a way that creates a competitive advantage for the organization. These critical success factors have been and will continue to be associated with employees, the working environment, including technology and equipment, and patients' satisfaction. Success in these areas should be realized via a clear corporate vision and steady strategic objectives.

NERH was established via the merge of seven, later eight hospitals with very poor preparation for the planned large changes among employees of the hospitals. The change period has lasted too long, which has been associated with the deviation of previously directed plans and, thereafter, with new approaches to the change directions. Medical process in NERH has gained stabilization and trends to upward. It still has no equal growth when compared to TUC but based on financial efficiency and investment capacity during the last three years NERH has competence to achieve the aims either medical or economical. Large effort has to be made by the political lobby to introduce NERH opinion and vision on health care system future in Estonia more efficiently. Cooperation with TUC fortifies the positions.

Evaluation of the change results is necessary at least after every five years period.

\section{References}

Alas, R.; Vadi, M. 2006. The impact of organizational culture on organizational learning and attitudes concerning the change from an institutional perspective, International Journal of Strategic Change Management 1(1/2): 155-170.

Alas, R.; \& Vadi, M. 2004. The impact of organizational culture on attitudes concerning the change in post-soviet organizations, Journal for East European Management Studies 9(1): 20-39.

Alas, R. \& Sharifi, S. 2002. Organizational learning and resistance to the change in Estonian companies, Human Resource Development International 5(3): 313-331.

Annual report of NERH 2002. Tallinn, NERH files.

Annual report of NERH 2003. Tallinn, NERH files.

Annual report of NERH 2004. Tallinn, NERH files.

Annual report of TUC 2001. Tallinn, TUC files. 
Annual report of TUC 2002. Tallinn, TUC files.

Annual report of TUC 2003. Tallinn, the TUC files.

Bakler, T. 2003. Hospital Master Plan`st haiglavõrgu arengukavani, Eesti Arst special edition: 23-27.

Clark, E. \& Soulsby, A. 1999. Organizational change in post-communist Europe: management and transformation in the Czech Republic. Routledge.

Ginsburg, P. B. 2004. Controlling health care costs, New England Journal of Medicine 351(16): 1591-1593.

Jesse, M.; Habicht, J.; Aaviksoo, A.; Koppel, A.; Irs, A. \& Thompson, S. 2004. Health care systems in transition, European Observatory on Health Systems and Politics 6(11).

Jüristo, T. 2004. What is the cost of health care? Presentation at NERH Annaual Conference.

Khadaroo, M. I. 2005. An institutional theory perspective on the UK's private finance initiative (PFI) accounting standard setting process, Public Management Review 7(1): 69-94.

Lane, J.-E. 2000. New Public Management. Routledge.

Lawton, A.; Rose, A. 1994. Organizations and management in the public sector. Second edition. Financial times. Pitman Publishing.

Nichol, L. M. 2002. Can defined contribution health insurance reduce costs? EBRI 246.
Overview of the feasibility study for Tartu University Hospital. 1999. Clinicum Newspapar 10/10.

Rainey, H. G. 1997. Understanding \& Managing Public organizations. Second edition. San Francisco: Jossey-Bass Publishers.

Scandinavian Care Consultants AB and SWECO. 2000. Estonian Hospital Master Plan 2015. Final report by Scandinavian Care Consultants AB and SWECO. Tallinn. Available from Internet: <www.sm.ee>.

Strunk, B. C. \& Ginsburg, P. B. 2004. Tracking health care costs: trends turn downward in 2003, Health Affairs 354(4).

Statement of Ministry of Social Affairs of Estonia. 2004. Requirement for Hospitals. Available from Internet: <www. sm.ee>.

Statement of Estonian Government nr 103 from 2.04.2003. Estonian Hospital Developmental Plan for 2015, Tallinn. Available from Internet: $<$ www.sm.ee $>$.

NERH. 2000. Hospital files.

Võrk, A.; Jesse, M.; Roostalu, I. \& Jüristo, T. 2005. Eesti tervishoiu rahastamissüsteemi jätkusuutlikkuse analüüs. PRAXIS, Tallinn.

World Health Organization Regional Office for Europe. 2005. European health for all database (HFA-DB). Available from Internet: <www.sm.ee>. 